\title{
Correction to: LC3B globular structures correlate with survival in esophageal adenocarcinoma
}

Shereen El-Mashed ${ }^{1,3}$, Tracey R. O'Donovan ${ }^{1}$, Elaine W. Kay ${ }^{2}$, Ayat R. Abdallah ${ }^{3}$, Mary-Clare Cathcart ${ }^{4}$, Jacintha O'Sullivan ${ }^{4}$, Anthony O'Grady ${ }^{2}$, John Reynolds ${ }^{4}$, Seamus O'Reilly ${ }^{5}$, Gerald C. O'Sullivan ${ }^{1}$ and Sharon L. McKenna ${ }^{1 *}$

\section{Correction to: BMC Cancer \\ https://doi.org/10.1186/s12885-015-1574-5}

Following publication of the original article [1], the authors reported an omission in the affiliations. Dr. Shereen El-Mashed should be affiliation to both 1 and 3 . This is reflected in this correction article.

\section{Author details}

'Leslie C. Quick Laboratory, Cork Cancer Research Centre, BioSciences Institute, University College, Cork, Ireland. ${ }^{2}$ Department of Pathology, Royal College of Surgeons Ireland (RCSI), Beaumont Hospital, Dublin, Ireland. ${ }^{3}$ National Liver Institute, Menoufiya University, Shebin El Kom, Egypt. ${ }^{4}$ Department of Surgery \& Trinity Centre for Health Sciences, St James Hospital, Dublin, Ireland. ${ }^{5}$ Department of Oncology, Cork University Hospital, Cork, Ireland.

Published online: 03 December 2019

\section{Reference}

1. El-Mashed, et al. LC3B globular structures correlate with survival in esophageal adenocarcinoma. BMC Cancer. 2015;15:582. https://doi.org/10. 1186/s12885-015-1574-5.

The original article can be found online at https://doi.org/10.1186/s12885015-1574-5

* Correspondence: s.mckenna@ucc.ie

${ }^{1}$ Leslie C. Quick Laboratory, Cork Cancer Research Centre, BioSciences

Institute, University College, Cork, Ireland

Full list of author information is available at the end of the article

C The Author(s). 2019 Open Access This article is distributed under the terms of the Creative Commons Attribution 4.0 International License (http://creativecommons.org/licenses/by/4.0/), which permits unrestricted use, distribution, and reproduction in any medium, provided you give appropriate credit to the original author(s) and the source, provide a link to the Creative Commons license, and indicate if changes were made. The Creative Commons Public Domain Dedication waiver (http://creativecommons.org/publicdomain/zero/1.0/) applies to the data made available in this article, unless otherwise stated. 